\title{
Indium In 111 Pentetate
}

National Cancer Institute

\section{Source}

National Cancer Institute. Indium In 111 Pentetate. NCI Thesaurus. Code C71725.

A sterile, non-pyrog enic, isotonic solution of radioactive indium In 111 diethylenetriamine pentaacetate (DTPA). When administered intrathecally, indium In 111 pentetate percolates up the spinal canal with the cerebrospinal fluid (CSF) to the basal cisterns of the posterior and middle cranial fossas. This agent is used in radionuclide cisternography to image the flow of CSF, for the identification of abnormalities in CSF circulation, for location of sites of CSF leakage, and for evaluation of CSF shunt patency. Normally, this agent does not penetrate into the brain ventricles. 